\title{
The Future of Animal-Source Food Demand and Supply in Africa
}

\author{
Dolapo Enahoro, ${ }^{1}$ Nhuong $\operatorname{Tran},{ }^{2}$ Chin Yee Chan, ${ }^{3}$ Adam Komarek, ${ }^{4,5}$ Karl M. Rich ${ }^{6,7}$
}

December 17, 2021

1. International Livestock Research Institute, c/o IWMI-Ghana, Accra, Ghana.

2. WorldFish, c/o Department of Fisheries, Yangon, Myanmar.

3. WorldFish, Penang, Malaysia.

4. International Food Policy Research Institute, Washington D.C., USA.

5. The University of Queensland, School of Agriculture and Food Sciences, Gatton, Qld 4343, Australia.

6. International Livestock Research Institute, Rue 18 Cité Mamelles, BP 24265 Ouakam, Dakar, Senegal.

7. Fergusson College of Agriculture, Master of International Agriculture Program and Department of Agricultural Economics, Oklahoma State University, Stillwater, OK 74078, USA.

This document is part of a series of short papers on "The Future of X", produced as part of foresight-related research supported by the CGIAR Research Program on Policies, Institutions, and Markets, and edited by Keith Wiebe (IFPRI) and Steven Prager (Alliance of Bioversity and CIAT). These short papers are intended to provide a focused, forward-looking perspective on key issues to support discussion on food, land, and water systems transformation. We thank two anonymous reviewers for their comments on an earlier draft.

This is an accepted version presented as a pre-print. It is currently undergoing final revision, editing, and production. A final version will be made available at http://foresight.cgiar.org.

\section{What is the issue?}

Demand for animal-source foods (ASF)* has grown substantially in Africa over the last four decades, fueled mainly by population growth, urbanization, and modest gains in per capita incomes [1]. Further growth over the medium and longer terms is expected as these trends in external drivers continue, although short-run disruptions are possible as COVID-oriented shifts persist in some contexts [2-4]. The implications of this growth are nuanced, reflecting a multitude of economic, environmental, and public health trade-offs rather than a definitive answer on their positive or negative effects (i.e., are these growth trends good or bad for Africa?) [5]. For instance, increased per capita consumption of ASF can affect food security and

\footnotetext{
* ASF in this study refers to foods of animal origin, i.e., meat, fish, milk, and eggs; while livestock-derived foods (LDF) are a subset of ASF that exclude fish.
} 
public health positively, e.g., through improved nutrition of populations with heightened nutritional needs [6, 7], but also negatively, e.g., due to an increased prevalence of diet-related non-communicable diseases [8]. Increased demand can also spur livelihood opportunities [9] and economic growth, including through international and intra-regional trade [10]. On the other hand, expanded livestock production can exacerbate negative environmental impacts related to land use, climate change, and water crises, among others [11].

The impacts of future demand for ASF in Africa will depend on which types of commodities and products (particularly processed ones) are increasingly consumed, whether the supply is met through imports or local production, and the modes of production, along with other considerations. Indeed, future scenarios based on an expansion of the status quo will have profoundly different impacts than those mediated by climate or disease shocks, or even by changes elsewhere, such as a transition in developed countries away from animal agriculture (e.g., through higher consumption of plant-based or lab-based meats/seafood). These differences make it important to consider alternative future scenarios and ways to achieve (or avoid) them.

\section{What research has been conducted so far?}

Recent studies applied the widely used global multi-market models, IMPACT and GLOBIOM, to analyze the future demand for livestock-derived food products (LDF) in Africa within country, regional, and global contexts to address and quantify these impacts and tradeoffs $[12,2,9,13,14]$. Similar studies have modeled the prospects and challenges of fish for food security in Africa [10,15]. A country-level study on livestock [12] that included eight countries in total (five in Africa), and another single-country study on fish in Zambia [15], placed the changing demand for ASF within the context of meeting multiple objectives for food security, nutrition, and livelihoods. Two regional studies further highlight options for increasing production capacity to meet ASF demand and realize socio-economic benefits, while sustainably managing natural resources and the environment $[9,10]$.

\section{What has research found?}

Based on historical, demographic, and climatic conditions, total demand for LDF in Africa is projected to increase fourfold for meat and two to threefold for milk between 2010 and 2050, with much of this increase accounted for by population growth $[2,16]$. Poultry meat production, which is projected to grow the fastest of all meat types, will expand by the most in West Africa, while East Africa, the largest consumer of milk traditionally, is projected to dominate the growth of milk demand to 2050 [2]. Similarly, total demand for fish and aquatic foods is projected to grow at $30 \%$ from $2020-2050$, although its consumption will fall on a per capita basis $[10,17]$. 
Based on the makeup of future demand, however, ASF products will contribute differently to overall nutrient profiles across countries. According to the livestock foresight studies, most countries in the region will see relative declines in the supply of nutrients that are better supplied by dairy and red meat (beef/lamb), while those nutrients obtained more from poultry meat and eggs increase in supply to 2050 [12]. Per capita fish consumption, which constituted nearly $20 \%$ of animal protein in the region in 2018 (Figure 1) [1], is projected to decline, resulting in the potential reductions of critical micronutrients in diets [10]. Production constraints that limit local availability mainly explain the decline in per capita consumption of fish [10]. As access to fish products and knowledge of their benefits improve, however, we could see growth in consumption of protein and micronutrient types that are essential for human development and particularly well suited for child growth [10, 12].

A. 2018

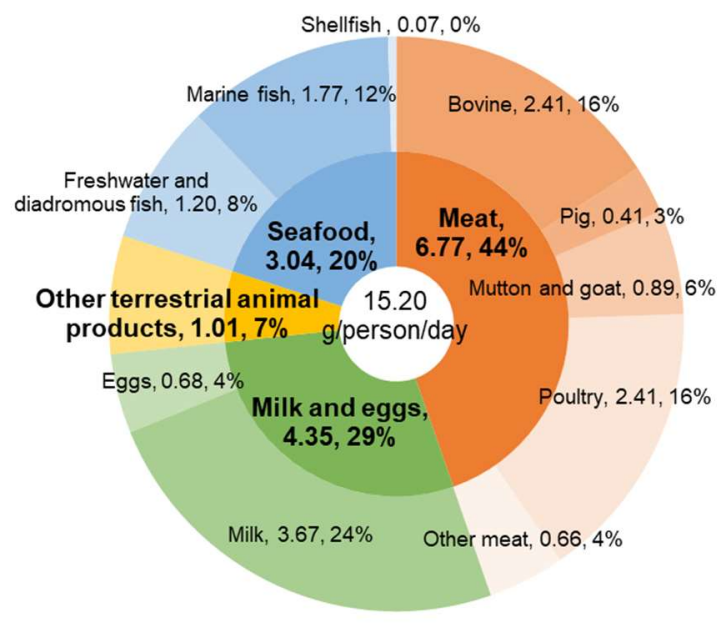

B. 2050

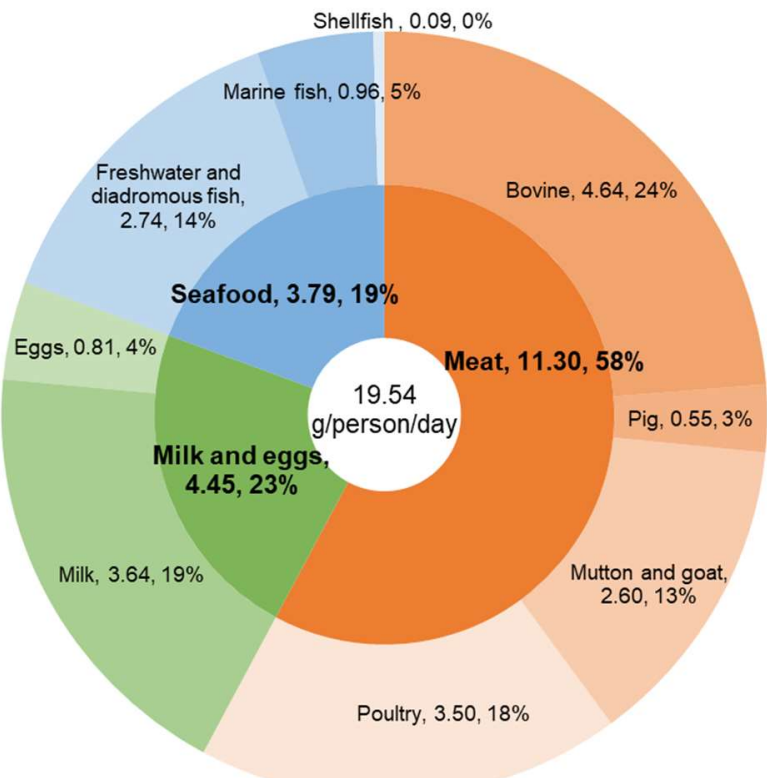

Figure 1. Distribution of ASF protein supply in Africa reported in 2018 and projected for 2050 (amounts in grams per person per day (g/cap/d) and composition in percent (\%)). (Data source: Panel A from FAO food balance sheets ${ }^{1}$; Panel B from IMPACT model simulations of 'business-as-usual' projections using IMPACT main (for livestock ${ }^{12}$ ) and IMPACT Fish (for fish ${ }^{10}$ ) model versions). IMPACT does not replicate for 2050, supply of all the livestock and other terrestrial animal products present in the 2018 (FAO) data. As such, the simulation of livestock products is more aggregated for the future year than in the baseline year. For all products in 2050, the per capita protein supply is generated from projections of total supply and (divided by) human population. The models do not factor individual or household factors in the calculation of per capita quantities. 
In general, the anticipated growth in local production does not match the projections of higher demand for livestock and fish products in Africa, with imports making up the difference. LDF import dependence is projected to become quite substantial in some products, for countries that have traditionally registered high levels of imports for these products, such as poultry meat in Ghana [12]. Imbalances between domestic production and demand are particularly high for foods with high income-elasticities of demand, including meat, dairy products, and aquatic food $[18,19]$. Also, low substitution between domestic and imported ASF products in some countries limits the usefulness of import-limiting policies for stimulating domestic production [15]. Under business-as-usual projections, imports of milk and poultry more than double by 2050, compared to 2010 levels [2]. Bovine and small ruminant meat imports also increase substantially $[2,9,12]$. In the case of fish, although the global aquaculture industry grows exponentially, Africa is not part of this growth because of insufficient investments in local capacity [17]. Fish imports thus increase substantially to meet future demand in the region [10].

Prospects of expanded production to 2050 in Africa raise concerns about continuous land conversion, environmental pollution, and other resource degradation $[2,16]$. These effects could become concentrated in peri-urban production centers close to cities and towns where ASF demand is expanding across Africa [20]. However, investments that boost animal productivity, and enable adoption and scale out sustainable management practices are shown to have merit for managing environmental impacts while maintaining food security and income benefits of ASF consumption and production [9].

\section{What gaps deserve further work?}

In exploring options to address the challenges associated with the livestock and fish sectors in Africa, appropriate accounting is needed for the variation and heterogeneity in the demand and trade of ASF in the region. Studies are needed that can quantitatively disaggregate future ASF demand by its key components of product types and sources (e.g., meat cuts, processed products), while associating these demand changes to emerging changes in production systems, production capacities, and socio-economic, cultural, and other factors. Better tools and data are necessary to address these (dis)aggregation issues, e.g., through linking the current suites of quantitative foresight tools to participatory foresight processes. Tools are also needed that can simultaneously include the demand and supply of both livestock and fish within the same analytical framework. This way substitutability of the products can be recognized, as well as trade-offs and complementarities related to nutrient provision, feed demand, land use, and environmental impacts.

While current studies quantify discrete impacts related to nutrition and the environment, additional work is required to better measure sector impacts on livelihoods and the whole economy, including the generation of indices that measure tradeoffs along these different dimensions. Such advances could improve the linkages of regional and country foresight 
projections to the policies and investments that will be required to support transformation of the livestock and fish sectors in Africa. Furthermore, mounting calls to reduce (particularly red meat) or replace (e.g., with meat substitutes) ASF consumption globally [21] have profound existential investment and related implications for Africa [9]. This is particularly true for the impacts on the future origin of animal protein, prices, trade, and product classes (i.e., are certain cuts and products more likely to be displaced by alternative sources?). These potential impacts need further investigation. Studies must also include action plans to mitigate the potential dislocation in rural economies if these novel products become mainstreamed. Similarly, reduced global financial support of the livestock, capture fisheries and aquaculture sectors could have consequences for the attainment of sustainable development goals (SDGs), potentially undoing progress that has been made in many African countries using livestock and aquatic food production as pathways out of poverty $[9,11]$. COVID-19 is also expected to play a key role in future ASF trajectories. While the agri-food sector may be showing greater resilience to pandemic-related disruptions, compared to other sectors for example [22], a general lowering of income levels could dampen ASF demand and supply growth, leading to differential impacts across Africa.

\section{Links to more information}

- IMPACT model: https://www.ifpri.org/project/ifpri-impact-model, accessed 28 November 2020.

- GLOBIOM model: https://iiasa.ac.at/web/home/research/GLOBIOM/GLOBIOM.html, accessed 28 November 2020.

\section{References}

1. FAO. FAOSTAT Database, Food and Agriculture Organization of the United Nations (FAO). Website accessed on [31/08/2021]. (2021).

2. Herrero, M., Havlík, P., McIntire, J., Palazzo, A. \& Valin, H. African Livestock Futures: Realizing the Potential of Livestock for Food Security, Poverty Reduction and the Environment in SubSaharan Africa. www.towardssaferworld.org (2014).

3. WorldBank. Fish to 2030 : Prospects for Fisheries and Aquaculture. World Bank Rep. Number 83177-GLB. World Bank, Washington, DC. (2013).

4. Bryson, J. R., Andres, L., Ersoy, A. \& Reardon, L. A year into the pandemic: shifts, improvisations and impacts for people, place, and policy. in Living with Pandemics: People, Place and Policy (eds. Bryson, J. R., Andres, L., Ersoy, A. \& Reardon, L.) 2-34 (Edward Elgar Publishing Ltd., 2021).

5. Moran, D. \& Blair, K. J. Review: Sustainable livestock systems: anticipating demand-side challenges. Animal (2021).

6. Alonso, S., Dominguez-Salas, P. \& Grace, D. The role of livestock products for nutrition in the first 1,000 days of life. Anim. Front. 9, 24-31 (2019). 
7. Thilsted, S. H. et al. Sustaining healthy diets: The role of capture fisheries and aquaculture for improving nutrition in the post-2015 era. Food Policy 61, 126-131 (2016).

8. Mathijs, E. Exploring future patterns of meat consumption. Meat Sci. 109, 112-116 (2015).

9. Enahoro, D. et al. Supporting sustainable expansion of livestock production in South Asia and Sub-Saharan Africa: Scenario analysis of investment options. Glob. Food Sec. 20, 114-121 (2019).

10. Chan, C. Y. et al. Prospects and challenges of fish for food security in Africa. Glob. Food Sec. 20, 17-25 (2019).

11. ILRI. Options for the livestock sector in developing and emerging economies to 2030 and beyond. Meat Futur. Ser. Geneva, Switz. World Econ. Forum (2019).

12. Enahoro, D., Lannerstad, M., Pfeifer, C. \& Dominguez-Salas, P. Contributions of livestockderived foods to nutrient supply under changing demand in low- and middle-income countries. Glob. Food Sec. 19, 1-10 (2018).

13. Komarek, A. M. et al. Income, consumer preferences, and the future of livestock-derived food demand. Glob. Environ. Chang. 70, 102343 (2021).

14. Enahoro, D., Bahta, S., Mensah, C., Oloo, S. \& Rich, K. M. Current and future trade in livestock products. Rev. Sci. Tech. Off. Int. Epiz., 40, (2021).

15. Tran, N. et al. Fish supply and demand for food security in Sub-Saharan Africa: An analysis of the Zambian fish sector. Mar. Policy 99, 343-350 (2019).

16. Havlik, P. et al. Global climate change, food supply and livestock production systems: A bioeconomic analysis. in Climate change and food systems: Global assessments and implications for food security and trade (ed. Elbehri, A.) 357 (Food and Agriculture Organization of the United Nations (FAO). pp 178-197, 2015).

17. Kobayashi, M. et al. Fish to 2030: The Role and Opportunity for Aquaculture. Aquac. Econ. Manag. 19, (2015).

18. Desiere, S., Hung, Y., Verbeke, W. \& D'Haese, M. Assessing current and future meat and fish consumption in Sub-Sahara Africa: Learnings from FAO Food Balance Sheets and LSMS household survey data. Glob. Food Sec. 1-11 (2018) doi:10.1016/j.gfs.2017.12.004.

19. Zhou, Y. \& Staatz, J. Projected demand and supply for various foods in West Africa: Implications for investments and food policy. Food Policy 61, 198-212 (2016).

20. Latino, L. R., Pica-Ciamarra, U. \& Wisser, D. Africa: The livestock revolution urbanizes. Glob. Food Sec. 26, 100399 (2020).

21. Willett, W. et al. Food in the Anthropocene: the EAT-Lancet Commission on healthy diets from sustainable food systems. Lancet 393, (2019).

22. FAO. Food Outlook - Biannual Report on Global Food Markets. (FAO, 2020). doi:10.4060/ca9509en. 